\title{
Proceeding
}

6th INSHS International Christmas Sport Scientific Conference, 11-14 December 2011. International Network of Sport and

Health Science. Szombathely, Hungary

\section{Laws of neurofeedback influence on condition of highly skilled gymnasts-women}

\author{
TATIANA STRIZHKOVA , LARISA CHERAPKINA, OLGA STRIZHKOVA
}

Department of Anatomy, Physiology, Sport Medicine and Hygiene, Siberian State University of Physical Education and Sport, Russia

\begin{abstract}
Strizhkova T,Cherapkina L, Strizhkova O. Laws of neurofeedback influence on condition of highly skilled gymnasts-women. J. Hum. Sport Exerc. Vol. 7, No. Proc1, pp. S194-S201, 2012. Carried out research showed that changes of complex-coordinated activity, self-estimation of functional condition and cardiointervalographic indexes of the highly skilled gymnasts-women after neurofeedback course depended on dynamics of cerebrum theta-, alpha-rhythm during the neurofeedback sessions and successfulness of the alpha-rhythm increasing technical skill mastery generally. The neurofeedback which was begun in follicular phase of ovarian-menstrual cycle (OMC) led to the most pronounced positive changes of functional condition self-estimation. This method conducted complex-coordinated activity improvement and vegetative parameters stabilization of sportswomen in ovulatory phase. The least neurofeedback efficiency was in luteal phase Key words: OVARIAN-MENSTRUAL CYCLE, FUNCTIONAL CONDITION.
\end{abstract}

Corresponding author. 644010 , fl. 148, b. 15, s. Maslennikova, c. Omsk, Russia.

E-mail: strishi85@mail.ru

6th INSHS International Christmas Sport Scientific Conference, 11-14 December 2011. International Network of Sport and Health Science. Szombathely, Hungary

JOURNAL OF HUMAN SPORT \& EXERCISE ISSN 1988-5202

(c) Faculty of Education. University of Alicante

doi:10.4100/jhse.2012.7.Proc1.22 


\section{INTRODUCTION}

Contemporary development of gymnastic sport types makes extremely high demands to gymnast readiness level. At the same time the increasing of training load can provoke overstrain and decreasing of competitive successfulness. In this context adoption of supplementary training methods to training process is urgently. The neurofeedback is a method which makes it possible to improve some parameters of functional condition by self-control of cerebrum bioelectrical activity (Pogadaeva, 2001; Tristan et al., 2002; Shandibina, 2008). At present the neurofeedback is intended for control of various cerebrum rhythms (SMR-, beta-, alpha-rhythms), but the most optimal is the using of the neurofeedback for alpha-rhythm parameters regulation in sport (Shtark et al., 1999).

Influence of the neurofeedback on psychophysiological and vegetative parameters of sportswomen organism functioning was showed in the researches of this method efficiency in sport. Also the dependence of the neurofeedback efficiency on the ovarian-menstrual cycle (OMC) phases coincident with the training beginning was revealed (Kal'sina, 2002; Tristan, 2005; Mernaya, 2008; Tristan et al., 2008). But specialization and skill of sportswomen was left out of account in these researches. Also the influence of the alpha-rhythm parameters neurofeedback on special readiness considering OMC phases was not studied. At this moment question about influence laws of cerebrum rhythm regulation on sportswomen functional condition is learned not enough.

Thereby the purpose of our research was to identify of interactions between dynamics of cerebrum bioelectrical activity during neurofeedback sessions and post-training functional condition of the gymnastswomen and changes of functional condition parameters considering OMC phases.

\section{MATERIAL AND METHODS}

The 88 sportswomen (49 females - main group, 39 - control), age 16-21 years (average age - 18 1 years) participated in the research. The 44 female practiced sports aerobic, 31 - art gymnastic, 7 - sports gymnastic, 6 - sports acrobatic. The sportswomen had following skills: Master of sport of international class -1 female, Master of sport -59 , Candidate for master of sport -28 .

The OMC phases were defined by doctor-gynecologist on base of anamnesis and basal temperature measuring which was logged by sportswomen after morning awakening and before getting up during two months. Follicular measuring by standard method was used in 9 cases. All sportswomen were divided into 3 groups according the OMC phase. The sportswomen who began research in follicular phase was part of the first group (38 females), in ovulatory - the second group ( 27 female), in luteal - the third group (23 female).

Training loads were equal in all researching groups.

The sportswomen of the main group held 15-days neurofeedback course intended for cerebrum alpharhythm power increasing by Pogadaeva's method (2001). The neurofeedback sessions were held by software-hardware complex engineered in Institute of molecular biology and biophysic SB RAMS. This complex consisted of multichannel interface BI-012 for computer monitoring, recording and play-back of electroencephalographic (EEG), electromyographic (EMG) and temperature signals, the kit of sensors and software "Boslab-alpha". The bipolar disposal was used for biopotentail recording. The EEG-electrodes were located according international system «10-20» (F1, P3), two EMG-electrodes were located on forehead (venter frontalis), thermoelectrode fastened on third finger of right hand. The neurofeedback 
sessions (duration of a session was 30 minutes) was held once per day before training and every day. The sportswoman received information about training successfulness after each session. Briefing and supplementary explaining about relaxation attainment during session (it was prerequisite for neurofeedback successfulness) was held before session for task achieving (the alpha-rhythm power increasing) (Schwartz, 1998). The task for sportswoman was increasing of feedback sounds frequency (it appeared when alpharhythm power was above threshold mean during 0.2 second) during neurofeedback session. Control of general tension was carried out by EMG index and temperature (Zakharova, 2002). Power of theta-, alphaand beta-rhythms were being recorded during neurofeedback sessions. The successfulness was estimated by classification of Svyatogor et al. (2000).

The gymnasts of the control group who did not held the neurofeedback course were examined with the sportswomen of the main group.

Neurofeedback influence on sportswomen complex coordinated activity was carried out with the using of Romberg's test (the pose 3) (Grigor'ev, 2010), test of the complex coordinating movement memorization, competitive program ideomotor execution (Pikkenhein, 1980) and competitive program execution by the upper limbs.

Electrocardiogram (ECG) was recorded by ECG complex "Poli Specter" in second standard disposal. The 5-minutes ECG recording (pre and post examination) was held with opened eyes in all groups.

ECG-recordings was analyzed by Baevsky's method of cardiointervalographic (CIG) (1997). The following indexes was analyzed: Mode (Mo) indicating dominating level of sinus node functioning, mode amplitude (AMo) reflecting mobilized influence measure of sympathetic system, variation swing (VS) demonstrating swing of cardio intervals means wavers, index of vegetative balance (IVB) showing ratio between sympathetic and parasympathetic systems, index of adequacy of regulation processes (IARP) indicating adequacy between sympathetic system activity and leading level of sino-atrial node, vegetative index of rate (VIR) made it possible to judge about parasympathetic changes of vegetative balance, tension index (TI) indicating the extent of centralization of heart rate regulation.

The questionnaire "Self-estimation of functional condition and training level" (Pogadaeva, 2002) was used for defining of neurofeedback influence on the sportswomen self-perception of their functional condition.

Statistical analysis of received data was conducted with using of software SPSS 13.0. Skewness and kurtosis was used for defining of the general population normalcy. Significance level of indexes changes was identified by Student t-test and Wilcoxon criterion. Spirmon's coefficient was used for correlation analysis. The level of significance was set the mean $p<0.05$.

\section{RESULTS}

The highly skilled gymnasts-women who have begun the neurofeedback course in ovulatory phase had the most pronounced influence of the training on complex coordinated activity. Particularly vestibular balance improved, time expending for complex coordinating movements memorization decreased and time of the competitive program execution by upper limbs approximated to the reference quantity. The improving of time of complex coordinating movements memorization and relative time of competitive program execution by upper limbs was revealed with the sportswomen who have begun the training in follicular OMC phase. The neurofeedback course beginning in luteal OMC phase favored as well as decreasing of time of 
complex coordinating movements memorization such optimization of relative time of competitive program ideomotor execution (Table 1).

Table 1. Parameters of complex coordinated activity of the main and control groups gymnastswomen in various $O M C$ phases, $M \pm m$

\begin{tabular}{|c|c|c|c|c|c|c|c|c|c|c|}
\hline \multirow{3}{*}{ Parameters } & \multirow{3}{*}{ 产 } & \multicolumn{9}{|c|}{ OMC phases } \\
\hline & & \multicolumn{3}{|c|}{ Follicular } & \multicolumn{3}{|c|}{ Ovulatory } & \multicolumn{3}{|c|}{ Luteal } \\
\hline & & Pre & Post & $\mathrm{p}$ & Pre & Post & p & Pre & Post & $p$ \\
\hline \multirow{2}{*}{ Time of Romberg's test (s) } & Main & $\begin{array}{c}18 \\
\pm 3,1\end{array}$ & $\begin{array}{c}20 \\
\pm 4,8\end{array}$ & - & $\begin{array}{c}14 \\
\pm 4,5\end{array}$ & $\begin{array}{c}24 \\
\pm 4,7\end{array}$ & $\overline{8}$ & $\begin{array}{c}11 \\
\pm 2,1\end{array}$ & $\begin{array}{c}20 \\
\pm 7,3\end{array}$ & - \\
\hline & Control & $\begin{array}{c}12 \\
\pm 2,0\end{array}$ & $\begin{array}{c}17 \\
\pm 4,6\end{array}$ & - & $\begin{array}{c}12 \\
\pm 1,4\end{array}$ & $\begin{array}{c}10 \\
\pm 2,5\end{array}$ & - & $\begin{array}{c}12 \\
\pm 3,3\end{array}$ & $\begin{array}{c}12 \\
\pm 2,5\end{array}$ & - \\
\hline \multirow{2}{*}{$\begin{array}{l}\text { Time of complex coordinating } \\
\text { movement memorization (s) }\end{array}$} & Main & $\begin{array}{r}108 \\
\pm 11,9\end{array}$ & $\begin{array}{c}74 \\
\pm 6,9\end{array}$ & $\overrightarrow{8}$ & $\begin{array}{c}121 \\
\pm 14,5\end{array}$ & $\begin{array}{c}64 \\
\pm 7,9\end{array}$ & চ & $\begin{array}{c}110 \\
\pm 24,7\end{array}$ & $\begin{array}{c}75 \\
\pm 8,3\end{array}$ & $\dot{8}$ \\
\hline & Control & $\begin{array}{c}105 \\
\pm 14,2\end{array}$ & $\begin{array}{c}109 \\
\pm 18,0\end{array}$ & - & $\begin{array}{c}110 \\
\pm 2,92\end{array}$ & $\begin{array}{c}123 \\
\pm 258\end{array}$ & - & $\begin{array}{c}93 \\
\pm 20,5\end{array}$ & $\begin{array}{c}118 \\
\pm 18,5\end{array}$ & - \\
\hline \multirow{2}{*}{$\begin{array}{c}\text { Relative time of competitive } \\
\text { program ideomotor execution } \\
(\%)\end{array}$} & Main & $\begin{array}{c}90 \\
\pm 3,9\end{array}$ & $\begin{array}{c}94 \\
\pm 2,9\end{array}$ & - & $\begin{array}{c}93 \\
\pm 4,3\end{array}$ & $\begin{array}{c}98 \\
\pm 3,3\end{array}$ & - & $\begin{array}{c}85 \\
\pm 3,6\end{array}$ & $\begin{array}{r}100 \\
\pm 4,3\end{array}$ & 8 \\
\hline & Control & $\begin{array}{c}90 \\
\pm 3,7\end{array}$ & $\begin{array}{c}91 \\
\pm 5,1\end{array}$ & - & $\begin{array}{c}99 \\
\pm 4,7\end{array}$ & $\begin{array}{c}91 \\
\pm 3,5\end{array}$ & - & $\begin{array}{c}80 \\
\pm 4,2\end{array}$ & $\begin{array}{c}84 \\
\pm 2,7\end{array}$ & - \\
\hline \multirow{2}{*}{$\begin{array}{l}\text { Relative time of competitive } \\
\text { program execution by upper } \\
\text { limbs (\%) }\end{array}$} & Main & $\begin{array}{c}87 \\
\pm 2,4\end{array}$ & $\begin{array}{c}97 \\
\pm 3.3\end{array}$ & 's & $\begin{array}{c}92 \\
\pm 3,1\end{array}$ & $\begin{array}{c}99 \\
\pm 33\end{array}$ & ㅇ. & $\begin{array}{c}88 \\
\pm 4,2\end{array}$ & $\begin{array}{c}92 \\
\pm 33\end{array}$ & - \\
\hline & Control & $\begin{array}{c}93 \\
\pm 3,7\end{array}$ & $\begin{array}{c}94 \\
\pm 3,5\end{array}$ & - & $\begin{array}{c}92 \\
\pm 1,8\end{array}$ & $\begin{array}{c}92 \\
\pm 3,8\end{array}$ & - & $\begin{array}{c}85 \\
\pm 3,6\end{array}$ & $\begin{array}{c}88 \\
\pm 3,2\end{array}$ & $\cdot$ \\
\hline
\end{tabular}

The study of the interactions between neurodynamic during neurofeedback sessions and complex coordinated activity parameters of sportswomen who have begun the training in follicular phase showed connections of neurofeedback successfulness with time of Romberg's pose keeping $(r=0.47 ; p<0.05)$ and with value of temporal error of competitive program execution by upper limbs taken by modulus ( $r=0.43$; $p<0.05)$. Post-training time of complex coordinating movements memorization was connected with alpharhythm average power of the sportswomen beginning the neurofeedback course in luteal phase $(r=0.61$; $p<0.05)$.

The analysis of the "backgrounds" ECG-recordings did not demonstrate significant changes of CIG-indexes of the sportswomen in various OMC phases after neurofeedback (Table 2). Meanwhile AMo, IVB, IARP, VIR and TI increased and also VS decreased of the sportswomen of the control group in ovulatory phase (Table 2). These changes indicated the increasing of processes centralization of heart rate regulation and the increasing of sympathetic system activity (Bruck et al., 2004). 
Table 2. Indexes of cardiointervalographic of the main and control groups gymnasts-women in various $O M C$ phases, $M \pm m$

\begin{tabular}{|c|c|c|c|c|c|c|c|c|c|c|}
\hline \multirow{3}{*}{ Indexes } & \multirow{3}{*}{ 总 } & \multicolumn{9}{|c|}{ OMC phases } \\
\hline & & \multicolumn{3}{|c|}{ Follicular } & \multicolumn{3}{|c|}{ Ovulatory } & \multicolumn{3}{|c|}{ Luteal } \\
\hline & & Pre & Post & p & Pre & Post & p & Pre & Post & $\mathrm{p}$ \\
\hline \multirow{2}{*}{$\begin{array}{l}\text { Mo } \\
\text { (s) }\end{array}$} & Main & $\begin{array}{c}0,88 \\
\pm 0,03\end{array}$ & $\begin{array}{c}0,89 \\
\pm 0,02\end{array}$ & $=$ & $\begin{array}{c}0,95 \\
\pm 0,04\end{array}$ & $\begin{array}{c}0,93 \\
\pm 0,02\end{array}$ & - & $\begin{array}{c}0,92 \\
\pm 0,07\end{array}$ & $\begin{array}{c}0,86 \\
\pm 0,05\end{array}$ & - \\
\hline & Control & $\begin{array}{c}0,94 \\
\pm 0,05\end{array}$ & $\begin{array}{c}0,87 \\
\pm 0,03\end{array}$ & $=$ & $\begin{array}{c}0,88 \\
\pm 0,05\end{array}$ & $\begin{array}{c}0,81 \\
\pm 0,04\end{array}$ & $=$ & $\begin{array}{c}0,94 \\
\pm 0,05\end{array}$ & $\begin{array}{c}0,90 \\
\pm 0,04\end{array}$ & - \\
\hline \multirow{2}{*}{$\begin{array}{l}\text { AMo } \\
(\%)\end{array}$} & Main & $37 \pm 2,5$ & $36 \pm 2,6$ & - & $35 \pm 2,8$ & $32 \pm 1,2$ & - & $30 \pm 2,5$ & $34 \pm 4,0$ & - \\
\hline & Control & $36 \pm 4,6$ & $35 \pm 2,3$ & $=$ & $26 \pm 1,9$ & $34 \pm 1,2$ & $<0,05$ & $35 \pm 1,8$ & $35 \pm 3,2$ & - \\
\hline \multirow{2}{*}{$\begin{array}{l}\text { VS } \\
\text { (s) }\end{array}$} & Main & $\begin{array}{c}0,43 \\
\pm 0,06 \\
\end{array}$ & $\begin{array}{c}0,46 \\
\pm 0,12\end{array}$ & - & $\begin{array}{c}0,38 \\
\pm 0,05 \\
\end{array}$ & $\begin{array}{c}0,39 \\
\pm 0,04 \\
\end{array}$ & - & $\begin{array}{c}0,40 \\
\pm 0,06\end{array}$ & $\begin{array}{c}0,42 \\
\pm 0,09\end{array}$ & - \\
\hline & Control & $\begin{array}{c}0,55 \\
\pm 0,12 \\
\end{array}$ & $\begin{array}{c}0,57 \\
\pm 0,16 \\
\end{array}$ & - & $\begin{array}{c}0,44 \\
\pm 0,07 \\
\end{array}$ & $\begin{array}{c}0,31 \\
\pm 0,02\end{array}$ & $<0,05$ & $\begin{array}{c}0,50 \\
\pm 0,14\end{array}$ & $\begin{array}{c}0,31 \\
\pm 0,02 \\
\end{array}$ & - \\
\hline \multirow{2}{*}{$\begin{array}{c}\text { IVB } \\
\text { (con.unit) }\end{array}$} & Main & $120 \pm 19$ & $121 \pm 19$ & - & $115 \pm 17$ & $96 \pm 13$ & $=$ & $92 \pm 17$ & $121 \pm 34$ & - \\
\hline & Control & $114 \pm 42$ & $98 \pm 19$ & - & $72 \pm 15$ & $116 \pm 11$ & $<0,01$ & $88 \pm 15$ & $118 \pm 17$ & - \\
\hline \multirow{2}{*}{$\begin{array}{c}\text { IARP } \\
\text { (con.unit) }\end{array}$} & Main & $45 \pm 4,8$ & $42 \pm 4,0$ & - & $38 \pm 4,1$ & $35 \pm 1,7$ & - & $35 \pm 4,1$ & $42 \pm 7,0$ & - \\
\hline & Control & $42 \pm 7,1$ & $41 \pm 4,0$ & - & $30 \pm 3,1$ & $42 \pm 2,1$ & $<0,05$ & $37 \pm 2,8$ & $39 \pm 4,0$ & - \\
\hline \multirow{2}{*}{$\begin{array}{c}\text { VIR } \\
\text { (con.uni) }\end{array}$} & Main & $\begin{array}{c}3,61 \\
\pm 0,44\end{array}$ & $\begin{array}{c}3,66 \\
\pm 0,42\end{array}$ & - & $\begin{array}{c}3,39 \\
\pm 0,39 \\
\end{array}$ & $\begin{array}{c}3,12 \\
\pm 0,34\end{array}$ & - & $\begin{array}{c}3,45 \\
\pm 0,55\end{array}$ & $\begin{array}{c}3,93 \\
\pm 0,76\end{array}$ & - \\
\hline & Control & $\begin{array}{c}3,11 \\
\pm 0,83\end{array}$ & $\begin{array}{c}3,17 \\
\pm 0,54\end{array}$ & - & $\begin{array}{c}3,18 \\
\pm 0,53 \\
\end{array}$ & $\begin{array}{c}4,37 \\
\pm 0,51\end{array}$ & $<0,05$ & $\begin{array}{c}2,70 \\
\pm 0,40 \\
\end{array}$ & $\begin{array}{c}3,71 \\
\pm 0,28 \\
\end{array}$ & - \\
\hline \multirow{2}{*}{$\begin{array}{c}\text { TI } \\
\text { (con.unit) }\end{array}$} & Main & $75 \pm 13,1$ & $72 \pm 12,9$ & - & $65 \pm 11,2$ & $52 \pm 7,5$ & - & $56 \pm 12,1$ & $79 \pm 26,3$ & - \\
\hline & Control & $69 \pm 28,7$ & $58 \pm 12,5$ & - & $43 \pm 9,8$ & $74 \pm 9,1$ & $<0,05$ & $46 \pm 7,7$ & $67 \pm 10,2$ & - \\
\hline
\end{tabular}

The correlation analysis of post ECG-examination results and course average EEG-indexes of the sportswomen who have begun the training in follicular phase showed that post-training values of AMo ( $\mathrm{r}=$ $0.64 ; p<0.001)$, VS $(r=0.48 ; p<0.05)$, IVB $(r=-0.46 ; p<0.05)$, IARP $(r=-0.66 ; p<0.001)$, VIR $(r=-0.48$; $p<0.05)$, TI $(r=-0.53 ; p<0.05)$ was connected with neurofeedback successfulness. Average theta-rhythm power during the neurofeedback sessions correlated with value of IARP $(r=0.56 ; p<0.05)$ and alpha-rhythm power correlated with value of cardiointervales Mo $(r=-0.73 ; p<0.001)$ of the gymnasts-women who have begun neurofeedback course in ovulatory phase. Course average alpha-rhythm power of the sportswomen beginning the training in luteal OMC phase was connected with VS $(r=0.74 ; p<0.01)$, IVB $(r=-0.68 ; p<0.05)$ and $\mathrm{TI}(r=-0.64 ; p<0.05)$.

The most significant changes of functional condition self-estimation were revealed when the neurofeedback course has been begun in follicular phase. The sportswomen who have begun the training in this phase noted the improving of self-feeling, attention, tactical thinking, the increasing of the emotional conditional control and self-reliance. The improving of memory was noted by sportswomen beginning the neurofeedback course in ovulatory OMC phase. Memory and attention of the sportswomen beginning the training in luteal phase improved. The sportswomen desire for creation got higher in all OMC phases.

The increasing of emotional condition control during workout was identified in the control group when preexamination has been conducted in follicular OMC phase only. 
The study of correlation showed that course average alpha-rhythm power correlated with self-estimation of emotional condition control during workout $(r=-0.51 ; p<0.01)$, course average theta-rhythm power correlated with desire for communication $(r=0.58 ; p<0.001)$, and neurofeedback successfulness was connected with self-estimation of activity $(r=0.43 ; p<0.05)$, analysis of technique and hold during workout $(r=0.53 ; p<0.01)$ and tactical thinking $(r=0.45 ; p<0.05)$ of the sportswomen who have begun the neurofeedback in follicular phase.

Connection of course average theta-rhythm power with self-reliance $(r=-0.57 ; p<0.05)$, self-estimation of capacity for work during workout $(r=-0.76 ; p<0,001)$ and with self-estimation of tactical thinking $(r=-0.59$; $p<0.05)$ was revealed in the group of the sportswomen who have begun the neurofeedback course in ovulatory OMC phase.

Course average theta-rhythm power of the sportswomen beginning the training in luteal phase correlated with self-estimation of academic results $(r=0.63 ; p<0.05)$, neurofeedback successfulness and average betarhythm power correlated with self-estimation of desire for creation (training successfulness $-r=-0.70$; $p<0.01$; beta-rhythm power $-r=-0.66$; $p<0.05$ ).

\section{DISCUSSION}

At present availability of interactions between EEG-indexes and some parameters of functional and emotional condition has been defined (Pryadein, 1989; Krause, 2000; Aftanas, 2004). But these laws were revealed with persons in relative quiet condition without self-regulation of their cerebrum bioelectrical activity. Summing up the results of our research about the study of laws of neurofeedback influence on the objective and subjective parameters of the gymnasts-women functional condition we can conclude that post-training values of these parameters correlate not only with alpha-rhythm power and neurofeedback successfulness but with course average theta- and beta-rhythms power also.

Connection of cerebrum alpha-rhythm with complex coordinated activity of musicians was showed in the Bazanova's $(2006,2008)$ and Shtark's (2007) researches. Probably self-increasing of alpha-rhythm power during neurofeedback sessions is a reason of revealed by us changes of complex coordinated activity of the highly skilled gymnasts-women. Also it is corroborated by the connections revealed during correlation analysis of alpha-rhythm power and successfulness of mastery of alpha-rhythm self-regulation technical skill with some parameters of complex coordinated activity. Herewith the neurofeedback using for sportswomen training favored the time decreasing of complex coordinating movements memorization in all OMC phases. Together with it the neurofeedback course made it possible to improve time of competitive program execution by upper limbs of sportswomen in follicular phase and processes of realization of technical skills generated earlier and to increase vestibular balance in ovulatory phase, to optimized time of competitive program ideomotor execution in luteal phase.

The Stepanyuk's (2009) and Cherapkina's (2009) researches demonstrated possibility of optimization of heart rate regulation processes of sportsmen without registration of their sport specialization by the neurofeedback (alpha-rhythm power) using. Our study of the "background" ECG-recordings of the highly skilled gymnasts-women showed that the neurofeedback using in the ovulatory OMC phase made it possible to stave off early the increasing of sympathetic system activity and centralization of heart rate regulation during OMC. Probable mechanism of this neurofeedback effect is the increasing of alpha-rhythm 
power during the neurofeedback sessions and relative with it the decreasing of theta-rhythm power. It is corroborated by revealed correlation.

The greatest number of indexes of questionnaire "Self-estimation of functional condition and training level" improved when the training have been begun in follicular phase, the least number in ovulatory and luteal OMC phases. At the same time Kal'sina (2002) defined the most significant changes of this questionnaire indexes in luteal phase while the neurofeedback begun in follicular phase was the least efficient. But in Kal'sina's research sport specialization was not considering.

\section{CONCLUSIONS}

The neurofeedback course intended for alpha-rhythm power increasing is the most efficient if it was began in follicular and ovulatory OMC phases.

The changes of complex coordinated activity of the highly skilled gymnasts-women connect with course average alpha-rhythm power and neurofeedback successfulness. Post-training CIG-indexes values connect with theta-, alpha-rhythms and neurofeedback successfulness. Post-training self-estimation of functional condition depends on the neurofeedback successfulness and course average theta-rhythm power.

\section{REFERENCES}

1. AFtANAS L, REVA N, VARLAMOV A, PAVLOV S, MAKHNEV V. Analysis of evoked EEG synchronization and desynchronization in conditions of emotional activation in humans: temporal and topographic characteristics. Neurosci. Behav. Physiol. 2004; 8(34):859-867.

2. BAEVSKY R, BERSENIOVA A. Assessment of organism adaptation abilities and risks of illness development; 1997.

3. BAZANOVA O, AFTANAS L. Successfulness of training and individual frequency-dynamic characteristics of alpha-activity. Bulletin of RAMS. 2006; 6:30-33.

4. BAZANOVA O, MERNAYA E, SHTARK $M$. The biofeedback in psychomotor training: electrophysiological basis. Russian physiological journal of I.M.Sechenov's name. 2008; 94 (5):539-556.

5. BRUCK M, MOLOTKOV O, GOLOFIEVSKII V, KORENEVSKII S. The organism functional condition of high school pupils with dependence from their professional orientation, sex and age. Medical scientific and learn-methodological journal. 2004; 22:80-88.

6. CHERAPKINA L. The dynamic of heart rate spectral characteristic of sportsmen who was held neurofeedback course. Omsk: IX All-Russian scientific conference of Biofeedback in medicine and sport. 2009; 108-114.

7. GRIGOR'EV A, ORLOV V, FITISOV O. Pre-nosological control and strengthening of somatic health and body functional reserves (medical technology "Health navigator"); 2010.

8. KAL'SINA V. The influence of the sexual dimorphism on successfulness and efficiency of the local alpha-stimulating training of the sportsmen. Dis. Cand. Med. Scien. Kurgan; 2002.

9. KRAUSE C, VIEMERO V, ROSENQVIST A, SILLANMAKI T, ASTROM T. Relative electroencephalographic desynchronization and synchronization in humans to emotional film content: an analysis of the 4-6, 6-8. 8-10 and 10-12 Hz frequency bands. Neuroscience Letters. 2000; 1(286):1-4. 
10. MERNAYA E, KONDRATENKO A, BAZANOVA O. The efficiency of alpha-EEG/EMG biofeedback session depends on neurohumoral status for musicians. Barnaul: VI Siberian physiological congress. 2008; 1:170-171.

11. PIKKENHEIN L. The neurophysiological mechanisms of ideomotor training. The questions of psychology. 1980; 3:116-120.

12. POGADAEVA O. The predictors of efficiency of the alpha-stimulating training using in sport: author's abstract of discand. biol. scien. Tomsk; 2001.

13. POGADAEVA O, CHERAPKINA L, BAIOVA N, KAL'SINA V, TRISTAN VV. The assessment of clinical efficiency of local alpha-stimulating training. Omsk: IV All-Russian scientific conference of Biofeedback in medicine and sport. 2002; 71-74.

14. PRYADEIN V. The individuality differences volitional activity and it typological preconditions. Dis. Cand. Psychol. Scien; 1989.

15. SCHWARTZ M. The contemporary problems of biofeedback. Novosibirsk: Biofeedback - 3: The theory and practice. 1998; 14-24.

16. SHANDIBINA V. The cerebral mechanisms of sportsmen functional condition changes after local alpha-stimulating training. Omsk: VIII All-Russian scientific conference of Biofeedback in medicine and sport. 2008; 152-158.

17. SHTARK M, TRISTAN VG. Biofeedback: the trajectory of the improvement (preface). Omsk: I AllRussian scientific conference of Biofeedback in medicine and sport. 1999; 3-5.

18. SHTARK M, BAZANOVA O. The biofeedback in psychomotor reactivity (report 1). The comparison analysis of biofeedback and usual performance practice. Human physiology. 2007; 4:24-32.

19. STEPANYUK I. The changes of heart rate variability indexes of sportsmen who was held neurofeedback course. Omsk: IX All-Russian scientific conference of Biofeedback in medicine and sport. 2009; 87-91.

20. SVYATOGOR I. The method of cerebrum potential biofeedback and clinical using of it. Biological. 2000; 1:5-7.

21. TRISTAN VG, POGADAEVE O, TRISTAN VV. The local alpha-stimulating training in sport: neurophysiological mechanisms and post-training effects. The theory and practice of physical culture. 2002; 7:7-9.

22. TRISTAN VG, SHANDIBINA V. The forming of phenomenon of sportsmen optimal functioning with the neurofeedback using. Novosibirsk: scientific conference of Biofeedback: new possibilities. 2008; 47-48.

23. TRISTAN VV. The neurophysiological mechanisms of neurofeedback successfulness of the various sport specialization sportsmen. Moscow: VII All-Russian scientific conference of Biofeedback in medicine and sport. 2005; 83-85.

24. ZAKHAROVA V, SHUBINA O. The biofeedback methods for stress-dependent illnesses treatment. Thermo-myographic training; 2002. 